EVS28

KINTEX, Korea, May 3-6, 2015

\title{
Control Strategies and Functional Safety for the Intelligent Stator Cage Drive (ISCAD)
}

\author{
Florian Bachheibl ${ }^{1}$, Gurakuq Dajaku ${ }^{2}$, Adrian Patzak ${ }^{1}$, Dieter Gerling ${ }^{1}$ \\ ${ }^{1}$ Universitaet der Bundeswehr Muenchen,D-85577 Neubiberg, florian.bachheibl@unibw.de \\ ${ }^{2}$ FEAAM GmbH, D-85577 Neubiberg
}

\begin{abstract}
The novel Stator Cage Drive marks a paradigm shift in electrical machine design by substituting layers of windings with stator bars that are short-circuited on one end of the machine. Those bars are individually fed from the opposite end of the machine, utilizing dedicated power electronic switches. Instead of being limited to one fixed MMF-distribution in the air gap, it is now possible to incorporate new degrees of freedom into the control strategy for such a machine, e.g. pole-switching during operation with an asynchronous rotor and the creation of selected harmonics. Compared to conventional designs of traction drives for HEVs or BEVs, this drive architecture achieves a better efficiency, both in peak operation and using common drive cycles, it is cheaper in manufacturing and it also provides better fail-safety. In order to obtain a high-quality MMF-distribution, a number of individually fed stator bars as high as 60 is preferable, which also implies a higher complexity of the control of this machine than for three-phase counterparts. If for example an induction type rotor is chosen, it is possible to vary the number of poles during operation, thus allowing the machine to always operate in the region of highest efficiency, which usually lies in the field weakening region for induction machines. An overview of the capabilities of the ISCAD-Drive is given, the applicability of well-known control methods is investigated and matters of functional safety in current measurement for a high number of phases are discussed.
\end{abstract}

\section{Introduction}

The introduction of electrical machines in traction applications has introduced a wholly different set of requirements that have to be met, if compared to industry drives. Among low cost, (fail)-safety and scalability, one of the most important requirements is overall drive-cycle efficiency. It is especially hard for machinedesigners to meet this very criterion with conventional electrical machines because they are by nature optimized for one specific operating point. This limitation doesn't hold true for the ISCAD-drive presented in [1], which allows for various adaptations of machine parameters to given operating points. The machine and its properties will be presented in section 2 of this publication, followed by an overview over applicable control methods, which is given in section 3, before an investigation is made, whether current-sensorless control or current measurement using semiconductors as shunt resistors could be qualified according to ISO 26262 in Section 4. 
The findings will be summarized in the conclusion to this work.

\section{The ISCAD-Machine}

Contrary to conventional machines, the stator winding consists of bars which are shortcircuited on one end of the machine. The bars are individually connected to half-bridges on the opposite axial end of the machine. Figure 1 shows a principle setup of the intelligent stator cage drive.

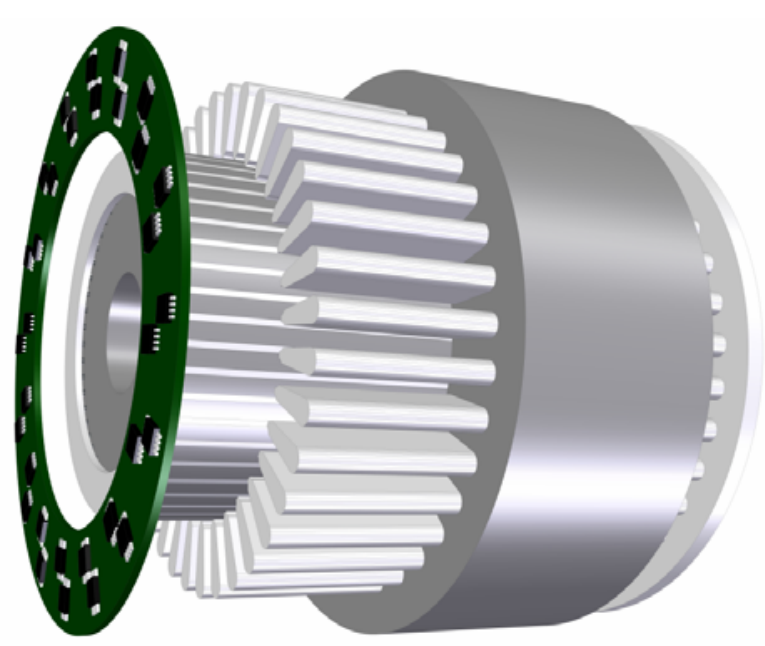

Figure 1: Principle setup of the ISCAD

\subsection{Properties of the drive system}

Whereas conventional drive systems with distributed or concentrated windings reach slot fill factors up to a little more than $60 \%$ [13], almost $100 \%$ are possible for the ISCADmachine. It could be manufactured using diecasting of aluminum, since, due to the higher slot fill factor, more cross-sectional area is available to compensate for the lower conductivity of aluminum. Therefore, the winding is lighter and can be produced more easily than windings that have to be wound using copper wires. Presumably, insulation between the aluminum bars and the iron core can be avoided, as the feed voltages are very low and also, because an oxidelayer can be formed at the interface between aluminum and iron before the die-casting process [2].

\subsection{Opportunities for control}

The current in every slot can be controlled individually, thus opening up multiple possibilities for controlling the machine.

\subsubsection{High-quality MMF}

Due to the high number of slots, an MMF with very high harmonic quality can be achieved, comparable to a distributed winding setup and even better.

\subsubsection{Pole-pair switching}

If pole-switching for more than two numbers of pole-pairs is supposed to be implemented in conventional machines, two or more windings have to be inserted into the stator of the machine [4],[5], thus reducing the slot fill factor drastically. This is no longer necessary for the ISCAD, since the assignment of a slot bar to one pole of the Stator-MMF is merely a virtual one and can be modified by changing one parameter in the supply function of that bar. The current in one stator bar $\mathrm{k}$ can be expressed as:

$$
\begin{aligned}
& I_{k}(t)=\sum_{i=p_{0}}^{\mathrm{p}_{\max }} \sum_{\mathrm{j} \mathrm{f}_{0}}^{\mathrm{f}_{\max }} \mathrm{A}_{\mathrm{i}, \mathrm{j}, \mathrm{k}}(\mathrm{t}) \cdot \\
& \cdot \cos \left(2 \pi \mathrm{jt}-\mathrm{i}(\mathrm{k}-1) \frac{2 \pi}{\mathrm{Q}_{\mathrm{s}}}+\varphi_{\mathrm{i}, \mathrm{j}, \mathrm{k}}(\mathrm{t})\right)
\end{aligned}
$$

In Equation ( 1$), p_{\max }$ is the highest number of pole-pairs present in the airgap-field, while $f_{\max }$ specifies the highest frequency. A is a timevarying amplitude, which can also be used to model the partial deactivation of a slot, explained in the following paragraph. Qs stands for the number of stator slots and $\varphi$ denotes an individual phase shift for every current-component. It is therefore possible to change the number of polepairs in induction machines during operation and even to supply the machine with two or more numbers of pole-pairs simultaneously. The number of pole-pairs can therefore be varied in a very smooth way, giving rise to the opportunity of using pole-fading as virtual gear set. A high number of pole-pairs could be selected during acceleration of an EV, while a low number of pole-pairs would help reduce iron loss at higher speeds. In summary, the number of pole-pairs being variable introduces a new degree of freedom to optimize the machine behavior over the whole drive cycle. This degree of freedom also enhances the machine concept called self-excited synchronous machine [6]. The 
stator of this machine is designed to create a space-harmonic MMF-wave which is used to supply the field windings of an inductively excited rotor shown in Figure 2. Inside an ISCAD-stator, this MMF-wave can be varied regardless of the fundamental wave. Applying multi pole-pairs to the MMF and being able to change their amplitudes individually would allow controlling flux and torque much more independently than in the conventional concept.

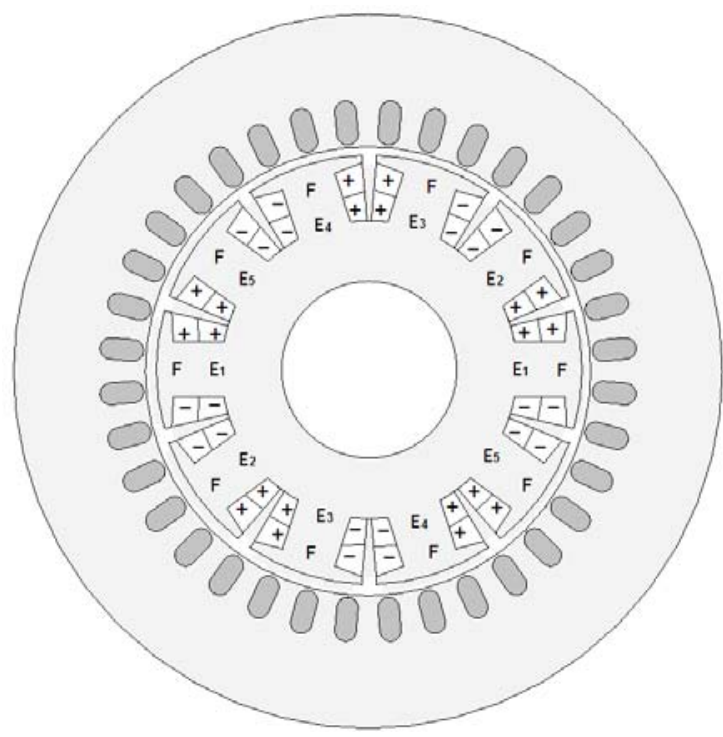

Figure 2: Self-Excited Synchronous Machine

\subsubsection{Partial deactivation of slots}

For operation points with reduced load, it may be beneficial to deactivate phases and connected half-bridges. This could be realized in a symmetrical or an asymmetrical pattern which may be fixed or rotating along the stator. As already mentioned, this behavior could be modelled inside the machine control by setting all amplitudes in ( 1 ) to zero for one slot.

\subsubsection{Synchronous-asynchronous hybrid machine}

There are already electrical machines which combine asynchronous and synchronous sources of torque - sequentially in time. Linestart motors use a squirrel cage, called damper cage, to generate torque at startup of the motor, until the rotor is pulled into synchronous operation. At that point, no current is induced into the squirrel cage and therefore, it does no longer contribute to torque production. Instead, an underlying synchronous source of Rotor-MMF interacts with the stator field to generate torque. This source may be a permanent magnet, rotor windings or flux barriers in the case of reluctance machines. The base for all these machines is that synchronous and asynchronous sources of torque do not interact. This principle can also be applied to the ISCAD, where different rotating fields can be superimposed to form the Stator-MMF. Similar to the above-mentioned pole-switching, it is also possible to have different current-components rotate with different angular frequencies. Therefore, a hybrid operation as synchronous machine and as induction machine is possible, giving room for even more degrees of freedom to optimize the electric drive both during design and during operation. If harmonic content is neglected, it is obvious that fields rotating with synchronous frequency do not interact with the induction part of the machine. Less obvious is the fact that asynchronous components of stator-MMF do not interact with e.g. the permanent magnets. According to [12], torque for generic rotating field machines amounts to:

$$
\begin{aligned}
\mathrm{T}=- & \mu_{0} \frac{1 \cdot \mathrm{r}}{\delta} \mathrm{p}_{2} \Theta_{\mathrm{d}, 1} \Theta_{\mathrm{d}, 2} \frac{1}{2} \cdot \\
& \cdot \int_{0}^{2 \pi} \sin \left(\left(\mathrm{p}_{1}-\mathrm{p}_{2}\right) \alpha-\right. \\
& \left.-\left(\omega_{1}-\Omega-\omega_{2}\right) \mathrm{t}+\varepsilon \mathrm{p}_{2}\right) \mathrm{d} \alpha
\end{aligned}
$$

Here, $1, r$ and $\delta$ represent the magnetic length, the airgap-radius and airgap-thickness, respectively. $\Theta, p, \Omega$ and $\omega$ denote the magneto-motive force, the number of pole-pairs, the rotor frequency and the angular frequency of the fields involved. Attribution of field quantities to stator and rotor is specified by indices 1 and 2 , respectively. Ultimately, $\varepsilon$ stands for a phase shift in the rotor field. Considering the integral in ( 2 ), it becomes obvious that no torque is produced at any point in time, if $\mathrm{p}_{1} \neq \mathrm{p}_{2}$. Furthermore, no net (timeaveraged) torque is produced if $\omega_{1} \neq \omega_{2}+\Omega$ or if $\varepsilon=0$. Consequently, if the number of polepairs of asynchronous and synchronous fields are different, they do not interact to produce torque. Possible realizations of this type of hybrid machine rely on a low-pole-pair synchronous component at the center of the rotor and a rotor cage near the surface which would be addressed by a high number of pole-pairs, as shown in Figure 3. The 
asynchronous field lines are closed in the rotor yoke, and therefore, the field is not perturbed by the flux barriers of the underlying reluctance machine. The same principle can be applied to combinations of induction rotors with pm-rotors or even synchronous, current-excited rotors.

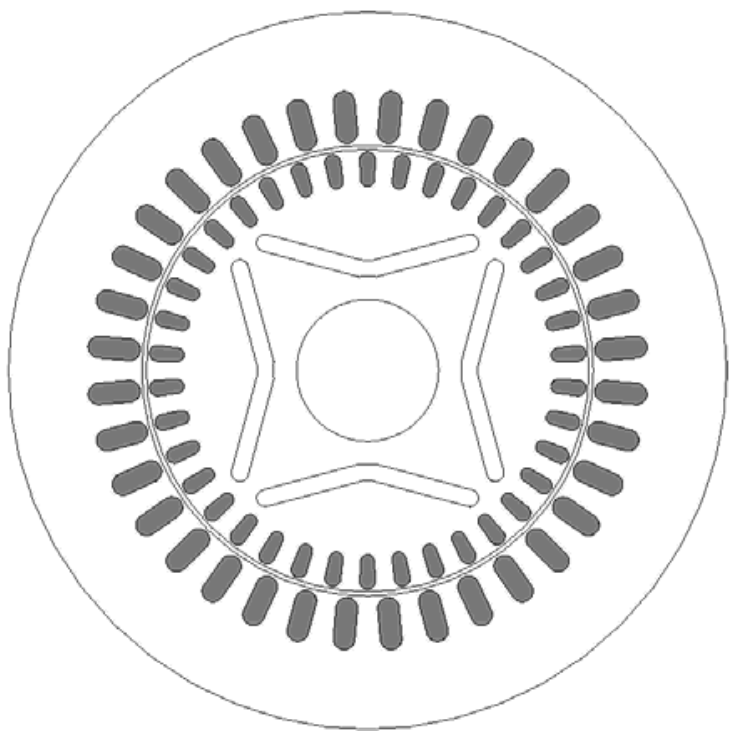

Figure 3: Hybrid rotor of type induction-reluctance

\section{Control methods applicable to the ISCAD}

The conventional, non-hybrid versions of ISCAD can be controlled using field-oriented control and direct torque control [7] but also predictive control [8]. Field-oriented control is possible analogously to three-phase machines, there are however more degrees of freedom in control [9]. These degrees of freedom are on the other hand difficult to handle in direct torque control strategies involving lookup-tables for spacevectors and variable switching-frequency. In the worst case, sub-harmonics are excited which amplify and cause loss. PWM-based direct torque control methods, such as deadbeat direct torque and flux control [10] do not suffer from this problem [11].

For hybrid variants, linear superposition of the fields involved can only be performed in the linear operating regions, i.e. for low torque demand. Better analytical models need to be developed in order to allow hybrid control also for higher values of saturation and crosssaturation. If two MMF-components with different frequency are created in the stator, they will create a pulsation of flux density. Even if both components create flux well beneath saturation, at the points of positive interference, saturation may be reached.

\section{Functional safety requirements to current accuracy}

As already mentioned, the machine has 60 phases which are supplied by individual half-bridges. For most methods of control, some information on the stator current is required. Since the use of one current sensor per stator bar is undesirable because of cost and package integration problems, in this section, functional safety requirements to current accuracy are first investigated in general, before a few words are spent on sensorless methods and on shunt-based current measurement. For increased safety, an Inverter Safety Unit following the idea presented in [25] is proposed. In order to perform a functional safety assessment according to ISO 26262 [2], this study concentrates on the event 'Unintended vehicle acceleration during a low speed maneuver amongst pedestrians' as defined in [14]. According to the authors, the event is classified as ASIL B which follows from the assessment shown in Table 1.

Table 1: Classification according to [14]

\begin{tabular}{|c|c|c|}
\hline Criterion & Class & Description \\
\hline Exposure & E3 & Medium probability \\
\hline Severity & S2 & $\begin{array}{c}\text { Severe and life- } \\
\text { threatening injuries, } \\
\text { survival probable }\end{array}$ \\
\hline Controllability & C3 & $\begin{array}{c}\text { Difficult to control } \\
\text { or uncontrollable }\end{array}$ \\
\hline
\end{tabular}

Following [14], a reasonable safety goal for the event under consideration would be that an unintended acceleration must not exceed $1.5 \mathrm{~m} / \mathrm{s}^{2}$ and that the event may not take longer than 1 second. This goal's main focus is to improve controllability of the event by the driver. If an electrically powered sedan such as Tesla's Model $\mathrm{S}$ is investigated, a curb weight of $2108 \mathrm{~kg}$ [22] means an accelerating force $\mathrm{F}=\mathrm{m} \cdot \mathrm{a}$ of 


$$
\mathrm{F}=2.108 \mathrm{~kg} \cdot 1.5 \frac{\mathrm{m}}{\mathrm{s}^{2}}=3,162 \mathrm{kN}
$$

which, using a wheel radius of $0.3515 \mathrm{~m}$ [22] as lever arm and a gear ratio of 9.73:1 translates to a maximum Torque error of $114 \mathrm{Nm}$ at the machine shaft. For this investigation, the machine is chosen to be equipped with an induction rotor, as presented in [1]. Therefore, the following equations apply [15]:

$$
\begin{aligned}
& \mathrm{L}_{\mathrm{S}, \text { Self }}=\frac{\pi}{2} \mu_{0} \frac{\mathrm{r}_{\text {bore }} 1_{\text {stack }}}{\delta} \\
& \mathrm{L}_{\mathrm{S}, \text { Main }}=\mathrm{L}_{\mathrm{S}, \text { Self }} \cdot \\
& \quad \cdot \sum_{\mathrm{k}=1}^{\text {floor }\left(\frac{\mathrm{S}_{\mathrm{s}}}{2 \mathrm{p}}\right)} \cos ^{2}\left(\mathrm{p}(\mathrm{k}-1) \frac{2 \pi}{\mathrm{Q}_{\mathrm{S}}}\right) \\
& \mathrm{i}_{\mathrm{Sd}, \text { max }}=\frac{\sqrt{2} \mathrm{U}_{\mathrm{S}}}{\omega_{\mathrm{S}}\left(1+\sigma_{\mathrm{S}}\right) \mathrm{L}_{\mathrm{S}, \text { Main }}} \\
& \hat{\mathrm{I}}_{\text {bar }}=\sqrt{\mathrm{i}_{\mathrm{Sd}}^{2}+\mathrm{i}_{\mathrm{Sq}}^{2}}
\end{aligned}
$$

Here, $\mathrm{r}_{\text {bore }}, 1_{\text {stack }}$ and $\delta$ denote the bore radius, the stack length and the air gap thickness, respectively. $p$ stands for the number of polepairs, Qs is the number of stator bars, $\omega_{\mathrm{S}}$ is the angular frequency of the stator field, $\sigma_{S}$ and $\sigma_{R}$ are stator and rotor stray parameters respectively. $i_{S d}$ and $i_{S q}$ are the magnetizing current and the quadrature current. The torque equation ( 8 ) refers to the steady state in stator reference frame [15],[16]:

$$
\mathrm{T}_{\mathrm{el}}=\frac{\mathrm{Q}_{\mathrm{s}}}{2} \mathrm{p} \frac{\mathrm{L}_{\mathrm{Sm}}}{1+\sigma_{\mathrm{R}}} \mathrm{i}_{\mathrm{Sd}} \mathrm{i}_{\mathrm{Sq}}
$$

The machine parameters of [1] are summarized in Table 2. Inserting the corner speed in ( 6 ) yields a magnetizing current $i_{S d}$ of $21 \mathrm{~A}$.

Table 2: Machine parameters

\begin{tabular}{|l|l|}
\hline \multicolumn{1}{|c|}{ Parameter } & \multicolumn{1}{c|}{ Value } \\
\hline $\mathrm{Q}_{\mathrm{S}}$ & 60 \\
\hline$\sigma_{\mathrm{S}, \mathrm{R}}$ & 0.05 \\
\hline $\mathrm{l}_{\text {Stack }}$ & $250 \mathrm{~mm}$ \\
\hline $\mathrm{r}_{\text {Bore }}$ & $75 \mathrm{~mm}$ \\
\hline$\delta$ & $0.5 \mathrm{~mm}$ \\
\hline $\mathrm{p}$ & 4 \\
\hline $\mathrm{n}_{\text {Corner }}$ & $53001 / \mathrm{min}$ \\
\hline $\mathrm{U}_{\mathrm{RMS}}$ & $8.4 \mathrm{~V}$ \\
\hline
\end{tabular}

For a torque error greater than $114 \mathrm{Nm}$ to occur at the machine shaft, necessary errors in current can now be calculated. To simplify the calculation, errors are assumed to be in amplitude only - a very obvious limitation since the method for obtaining the current distribution presented in section 4.2 relies on shunt-based measurements which are not prone to timing or angular errors. In order to accommodate this assumption, ( 8 ) is rewritten to form:

$$
\mathrm{T}_{\mathrm{set}}+\mathrm{T}_{\mathrm{err}}=\mathrm{Ai}_{\mathrm{Sd}}(1+\lambda) \mathrm{i}_{\mathrm{Sq}}(1+\lambda)
$$

with $T_{\text {err }}$ being the error-torque, $\lambda$ being the error in current and $\mathrm{A}$ being:

$$
\mathrm{A}=\frac{\mathrm{Q}_{\mathrm{s}}}{2} \mathrm{p} \frac{\mathrm{L}_{\mathrm{Sm}}}{1+\sigma_{\mathrm{R}}}
$$

$\lambda$ can obviously be calculated to:

$$
\lambda=\frac{1}{2}\left(-2+\sqrt{4+4\left(\frac{\mathrm{T}_{\text {err }}}{\mathrm{T}_{\text {set }}}\right)}\right)
$$

It is therefore dependent on the actual torque demand. For a maximum permissible torque error of $\mathrm{T}_{\mathrm{err}}=114 \mathrm{Nm}$ as calculated above, Figure 4 shows the relative current error $\lambda$ as a function of the set torque.

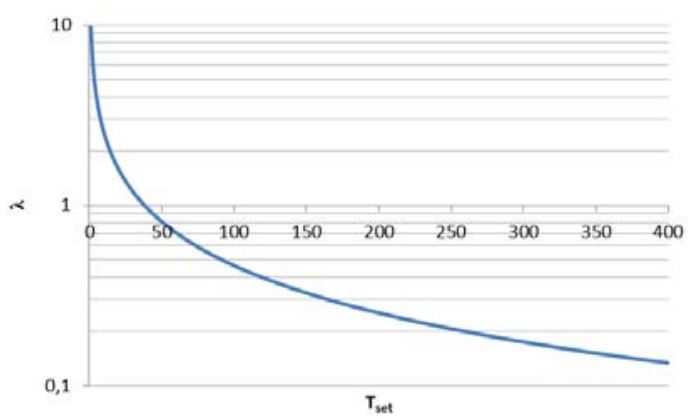

Figure 4: $\lambda$ as a function of $\mathrm{T}_{\text {set }}$

In the following, two methods for current estimation are investigated regarding their capability of maintaining the limits shown in this section. 


\subsection{Current-sensorless control}

The use of one current sensor in the DC-link to measure all phase-currents sequentially, as proposed in [17] is generally possible. However, using this method, the time allocated on the insertion of measurement vectors is not available for torque production. This might become problematic for a machine with phase numbers in the order of 60 . Another method using one current sensor in the DC-link is proposed in [18]. Here, the machine state is obtained from the DC power, under the assumption of a lossless inverter, the dynamics equation and a speed sensor at the machine shaft. A method that spares the current sensor in the DC-circuit is proposed in [19]. Here, currents are reconstructed using a state observer. For better accuracy, DC-voltage is measured, but this sensor can be omitted if the DC-voltage is sufficiently constant. An ISCADstator with a synchronous reluctance rotor could be controlled only with an encoder using an approach presented in [20]. Summing up, there are numerous methods available for a currentsensorless control of ISCAD-based machines. The accuracy of sensorless methods depends on the knowledge of the controlled system. Because of its simplicity, this knowledge is presumably better for an ISCAD-drive than for wound machines and therefore, current-sensorless control should yield good performance in this drive system.

\section{2 $\mathrm{U}_{\mathrm{DS}}$-based current-sensing}

Using the voltage drop across the power semiconductors is a possible way of estimating current through the devices. However, this method requires temperature compensation for the change in semiconductor resistance with temperature. Even if this effect is considered, there remains an uncertainty from manufacturing variations. No source on manufacturing tolerances of MOSFET-devices and especially on tolerances in $\mathrm{R}_{\mathrm{DSon}}$ could be found, except for an application note [23] indicating that the variance band is symmetrical to the typical values in Figure 5 and a datasheet for a low-voltage, highcurrent MOSFET [24] which provides resistance values for different junction temperatures. Figure 5 displays the information on typical and maximum values and the minimal values are gained assuming symmetry as stated above for the MOSFET specified in datasheet [24].

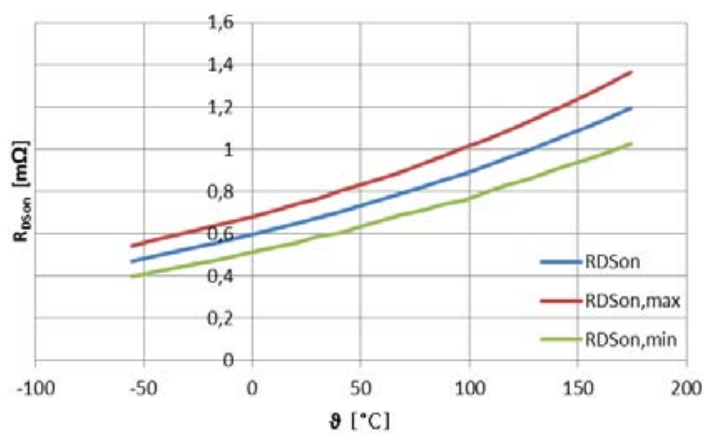

Figure 5: Variation in $\mathrm{R}_{\mathrm{DSon}}$

The drain-source-resistance could be used to measure current using the voltage-drop over this resistance. If however the real resistance value varies from the assumed value according to:

$\mathrm{R}_{\mathrm{DSon}}=\mathrm{R}_{\mathrm{DS} \text { on, assumed }}(1+\varepsilon)$

then

$I_{\text {Meas }}=\frac{I_{\text {Real }} \cdot R_{\text {DSon }}}{R_{\text {DSon, assumed }}}$

Since it could be shown that a deviation of the measured current from the real current value of $\lambda$ is acceptable, the following holds true:

$$
\begin{aligned}
& \mathrm{I}_{\text {Real }}(1+\lambda)= \\
& =\frac{\mathrm{I}_{\text {Real }} \cdot \mathrm{R}_{\text {DSon,assumed }}(1+\varepsilon)}{\mathrm{R}_{\text {DSon, assumed }}}
\end{aligned}
$$

and therefore: $\lambda=\varepsilon$. Figure 4 reveals the maximum value for $\lambda$ and, consequently, also for $\varepsilon$. From Figure 5 can be deduced, that the maximum relative deviation between the typical, assumed value for $R_{D S o n}$ and the erroneous values $R_{D S o n, m a x}$ and $R_{D S o n, m i n}$ is 0.154 p.u.. For a set torque of less than $340 \mathrm{Nm}$, the current accuracy of $\mathrm{R}_{\mathrm{DSon}}$-based measurement is therefore sufficient to guarantee a classification according to ASIL B. Even more, since a parallel operation of MOSFETs is planned for the application [21][17], the difference in resistances is averaged between all semiconductors.

\subsection{Using a safety unit to enhance functional safety}

The authors of [25] propose a so-called invertersafety-unit or ISU to create a redundant system for the supervision of applied torque. The ISU is able to disconnect the inverter from the power-net if an 
error is detected. In this case, the detection of errors is however based on electrical parameters, namely phase current and voltage. For a 60 -phase system, this method would be very costly and the methods discussed in sections 4.1 and 4.2 are aimed at trying to avoid the necessity for (accurate) current sensors. Therefore, we suggest the use of an acceleration-based safety unit in order to monitor the drive. If an excessive acceleration is detected, the inverter unit could be switched off.

\section{Conclusion}

The Intelligent Stator Cage Drive is a very powerful new drive topology. Not only does it allow a very versatile operation of conventional electric machines, using pole-switching, but does also increase the solution region for the design of hybrid electrical machines. Tailoring this machine to its application allows for load-cyclebased operation and will certainly give room for plenty of further research. This publication made an attempt at investigating which readily available methods for control are applicable to the design and investigated the aspect of functional safety in current measurement and torque control. It could be shown that current measurement in all phases is not necessary to reach a low risk ASIL classification. In future research, a method for the optimal selection of the number of pole-pairs will be presented. A prototype will be built to investigate this method and also the unconventional strategies such as hybrid operation, multi-pole-pair operation, deactivation of bars and pole-fading will be implemented on the prototype.

\section{References}

[1] G. Dajaku and D. Gerling, Low Costs and High Efficiency Asynchronous Machine with Stator Cage Winding, 2014 IEEE International Electric Vehicle Conference, Florence, 2014.

[2] C.A. da Silva, et.al., Rotor Cage of Single-Phase Induction Motors - Process Analysis, 2009 IEEE Electric Machines and Drives Conference, Miami, 2009.

[3] ISO 26262 (all parts), Road vehicles - functional safety, International Standard, 2011.

[4] V. Ostovic, Pole-Changing Permanent-Magnet Machines, IEEE Transactions on Industry Applications, Vol. 38, No. 6, 2002.

[5] G. Müller, Grundlagen elektrischer Maschinen, ISBN 3-52728-390-0, Weinheim, Wiley-VCH, 1994.

[6] G. Dajaku and D. Gerling, New Self-Excited Synchronous Machine with Tooth Concentrated Winding, 2nd International Electric Drives and Production Conference (EDPC-2013), October 29.-30., Nuremberg, Germany, pp. 217-222, 2013.

[7] E. Levi, et. al., Multiphase induction motor drives - a technology status review, IET Electric Power Applications, Vol. 1, No.4, pp. 489-516, 2007.

[8] M.R. Arahal, et. al., Multi-Phase current control using finite-state model-predictive control, Control Engineering Practice, Vol. 7, No. 5, pp. 579-587, 2009.

[9] H.A. Toliyat, A DSP-Based Vector Control of Five-Phase Synchronous Reluctance Motor, 2000 IEEE Industry Applications Conference, Rome, 2000 .

[10] B.H. Kenny and R.D. Lorenz, Stator and Rotor Flux Based Deadbeat Direct Torque Control of Induction Machines, 2001 IEEE Industry Applications Conference, Chicago, 2001.

[11] R. Bojoi, et. al., Direct torque control for dual three-phase induction motor drives, IEEE Transactions on Industry Applications, Vol. 41, No. 6, pp. 1627-1636, 2005.

[12] D. Gerling, Electrical Machines, ISBN 978-3-64217584-8, Berlin Heidelberg, Springer, 2015.

[13] P. Stenzel, et al., Innovative Needle Winding Method Using Curved Wire Guide in order to Significantly Increase the Copper Fill Factor, 
International Conference on Electrical Machines and Systems, ICEMS, Hangzhou, 2014.

[14] J. Birch, et al., Safety cases and their role in ISO 26262 functional safety assessment, in Computer Safety, Reliability and Security, pp. 154-165, Vol. 8153, Springer Berlin Heidelberg, 2013.

[15] D. Gerling, Analytical Calculation of the Novel Stator Cage Machine, 2015 IEEE International Electric Machines and Drives Conference, Coeur d'Alene, 2015, to be published.

[16] D.W. Nowotny and T.A. Lipo, Vector Control and Dynamics of AC Drives, ISBN 0-19856439-2, Oxford University Press, New York,1996.

[17] H. Kim and T.M. Jahns, Phase Current Reconstruction for AC Motor Drives Using a DC Link Single Current Sensor and Measurement Voltage Vectors, IEEE Transactions on Power Electronics, Vol. 21, No. 5, pp.1413-1419, 2006.

[18] G. Barba, et. al., Current Sensorless Induction Motor Observer and Control for Hybrid Electric Vehicles, 2001 IEEE 32 ${ }^{\text {nd }}$ annual Power Electronics Specialists Conference, Vancouver, 2001.

[19] S.-C. Chang and S.-N. Yeh, Current sensorless field-oriented control of induction motors, IEEE Proceedings on Electric Power Applications, Vol. 143, No. 6, pp. 492-500, 1995.

[20] T. Matsuo and T.A. Lipo, Current Sensorless Field Oriented Control of Synchronous Reluctance Motor, 1993 IEEE Industry Applications Society Annual Meeting, Toronto, 1993.

[21] A. Patzak and D. Gerling, Design of a MultiPhase Inverter for Low Voltage High Power Electric Vehicles, 2014 IEEE International Electric Vehicle Conference, Florence, 2014.

[22] Tesla Motors Website, Specifications of Tesla Model S, http://teslamotors.com/models/specs, accessed on 2015-01-26.

[23] D. Graovac, Parallel Operation of Power MOSFETs, Infineon Application Note, Neubiberg, 2009.

[24] Infineon Technologies, MOSFET OptiMOS Power-Transistor 60 V IPT007N06N Data Sheet Rev. 2.1, Infineon Technologies AG, Neubiberg 2014.
[25] S. Poledna and B. Gstöttenbauer, Functional Safety in the electric drivetrain, 2010 VDI-Tagung Baden-Baden Spezial, VDI-Berichte 2098, VDIVerlag, Düsseldorf, 2010.

\section{Authors}

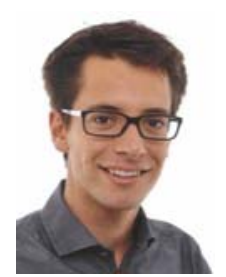

Florian Bachheibl M.Sc. graduated from the Universitaet der Bundeswehr Muenchen in 2011 with a Master of Science in mechatronics engineering. Since then, he has worked as a research assistant at the Institute of Electrical Drives and Actuators (Universitaet der Bundeswehr Muenchen, Werner-Heisenberg-Weg 39, 85579 Neubiberg, Germany. Phone: +49 896004 4838; email: florian.bachheibl@unibw.de.) His main research interests are the modelling of passive components, systems engineering and fields analysis.

Gurakuq Dajaku got his diploma degree in electrical engineering from the University of Prishtina, Kosova, in 1997 and the Ph.D. degree from the Universitaet der Bundeswehr Muenchen, Munich, Germany, in 2006. Since 2007 he has been a Senior Scientist with FEAAM $\mathrm{GmbH}$, an engineering company in the field of electric drives. Since 2008 and 2010 he has been a Lecturer at the Universitaet der Bundeswehr Muenchen, Germany, and the University of Prishtina, Kosova, respectively. His research interest is in the field of electrical machines and drives. He has published numerous technical papers in different IEEE

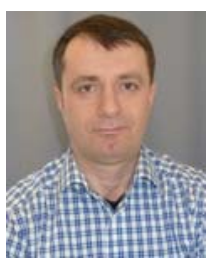
journals and conferences and has several international patents and patent pending applications. Dr. Dajaku received the Rheinmetall Foundation Award 2006 and the ITIS (Institute for Technical Intelligent Systems) Research Award 2006.

Adrian Patzak M.Sc. is research member at the Institute of Electrical Drives at the University of Federal Defense Munich, Werner-HeisenbergWeg 39, D-85577 Neubiberg, Germany (phone: +49 89 6004-3590; fax: $\quad-3718 ; \quad$ email: 
Adrian.Patzak@unibw.de). Adrian Patzak was born in 1985 and received his Master degree in Electrical Engineering from the University of Applied Sciences Regensburg, Germany, in 2011. Afterwards he switched to the University of Federal Defense Munich, and since that he is working as a research assistant on Automotive Power Systems, Electric Machines and Control

\section{Prof. Dr.-Ing. Dieter Gerling}

Institute for Electrical Drives, University of Federal Defense Munich, Werner-Heisenberg-Weg 39, 85579 Neubiberg, Germany. Tel: +49 896004 3708, Fax: +49 8960043718

Email: dieter.gerling@unibw.de

URL: www.unibw.de/EAA

Born in 1961, Prof. Gerling got his diploma and Ph.D. degrees in Electrical Engineering from the Technical University of Aachen, Germany in 1986 and 1992, respectively. From 1986 to 1999 he was with Philips Research Laboratories in Aachen, Germany as Research Scientist and later as Senior Scientist. In 1999 Dr. Gerling joined Robert Bosch $\mathrm{GmbH}$ in Bühl, Germany as Director. Since 2001 he is Full Professor and Head of the Institute of Electrical Drives at the University of Federal Defense Munich, Germany. 